\title{
Reply to Wiwanitkit: MRI finding in vaccine-associated paralytic poliomyelitis
}

\author{
José Roberto Lopes Ferraz-Filho • \\ Ulysses dos Santos Torres • \\ Eduardo Portela de Oliveira • Antonio Soares Souza
}

Received: 2 June 2010 /Accepted: 14 June 2010 /Published online: 26 June 2010

(C) Springer-Verlag 2010

Sir,

We thank Wiwanitkit [1] for his critical comments on our recently published paper [2].

As we stressed in the text [2], other entities must be considered in the differential diagnosis of poliomyelitis on MRI. The reported finding (lesions with increased signal intensity on $\mathrm{T} 2-\mathrm{W}$ images involving the spinal cord), therefore, is logically nonspecific. Nevertheless, it is appropriate to point out that the involvement of the anterior horns of the spinal cord showed by MRI demonstrate a pathological process by which poliomyelitis is characterized [3], and postmortem histological analysis in a case of poliomyelitis has shown the occurrence of pathological changes in an exact correlation with areas of lesions revealed by MRI [4].

Notwithstanding the scarceness of data on MRI characteristics of poliomyelitis (most of the wild-type cases occurred before the ample availability of MRI, and vaccine-associated cases are rarely reported), the significant role of this method in the diagnosis of poliomyelitis in a context of acute flaccid paralysis has been proposed in the literature [3-7].

J. R. L. Ferraz-Filho $(\bowtie) \cdot$ U. dos Santos Torres •

E. P. de Oliveira $\cdot$ A. S. Souza

Department of Radiology, Hospital de Base,

São José do Rio Preto Medical School,

Avenida Brigadeiro Faria Lima, 5544,

São José do Rio Preto, São Paulo 15090-000, Brazil

e-mail: jrl.ferraz@terra.com.br
We believe that this consecutively reported MRI finding $[3,5,6]$, albeit rare, should not be ignored. In addition, we agree with other authors [3-7] on the complementary role of MRI in the diagnosis of this disease. From a practical point of view, in a compatible clinical and epidemiological setting, the hypothesis of vaccine-associated paralytic poliomyelitis should be considered when an MRI reveals involvement of the anterior horns of the spinal cord.

\section{References}

1. Wiwanitkit V (2010) MR finding in vaccine-associated paralytic poliomyelitis. Pediatr Radiol. doi:10.1007/s00247-010-1752-1

2. Ferraz-Filho JR, Dos Santos Torres U, de Oliveira EP et al (2010) MRI findings in an infant with vaccine-associated paralytic poliomyelitis. Pediatr Radiol. doi:10.1007/s00247-010-1650-6

3. Kornreich L, Dagan O, Grunebaum M (1996) MRI in acute poliomyelitis. Neuroradiology 38:371-372

4. Wasserstrom R, Mamourian AC, McGary CT et al (1992) Bulbar poliomyelitis: MR findings with pathologic correlation. AJNR 13:371-373

5. Malzberg MS, Rogg JM, Tate CA et al (1993) Poliomyelitis: hyperintensity of the anterior horn cells on MR images of the spinal cord. AJR 161:863-865

6. Choudhary A, Sharma S, Sankhyan N et al (2010) Midbrain and spinal cord magnetic resonance imaging (MRI) changes in poliomyelitis. J Child Neurol 25:497-499

7. Arya SC, Agarwal N (2006) Clinical presentations of acute paralytic poliomyelitis. Vaccine 24:4263 